\section{Preventing crime by people with schizophrenic disorders: the role of psychiatric services}

\author{
S. HODGINS and R. MÜLLER-ISBERNER
}

\section{Background Knowledge of when and how to implement treatments to prevent criminal offending among people with schizophrenia is urgently needed.}

\begin{abstract}
Aims To identify opportunities for interventions to prevent offending among men with schizophrenic disorders by tracking their histories of offending and admissions to hospital.
\end{abstract}

Method We examined 232 men with schizophrenic disorders discharged from forensic and general psychiatric hospitals. Data were collected from participants, family members and official records.

Results More than three-quarters (77.8\%) of the forensic patients had previously been admitted to general psychiatric services; $24.3 \%$ of the general psychiatric patients had a criminal record. Offences had been committed by $39.8 \%$ of the forensic patients and $10.8 \%$ of the general psychiatric patients before their first admission to general psychiatry, and after their first admission these 59 patients committed 195 non-violent and 59 violent offences. Subsequently, 49 of them committed serious violent offences that led to forensic hospital admission. The offenders were distinguished by a pervasive and stable pattern of antisocial behaviour evident from at least mid-adolescence.

\section{Conclusions Generalpsychiatry} requires resources in order to prevent criminal offending among a subgroup of patients with schizophrenic disorders.

Declaration of interest None. Funding detailed in Acknowledgements.
Investigations of birth and population cohorts have found that people who develop schizophrenia are at increased risk (compared with the general population) of non-violent offending, and are at even higher risk of violent offending (Arseneault et al, 2000; Brennan et al, 2000; Mullen et al, 2000) and of homicide (Erb et al, 2001). The proportion of people who have or who are developing schizophrenia who are convicted of crimes varies by country, and parallels but exceeds the proportions of criminals in the general population (Mullen et al, 2000; Hodgins \& Janson, 2002). In order to incorporate interventions designed to reduce offending into mental health services, it is necessary to know when offending begins, when such individuals first contact psychiatric services, and the problems that they present at first contact.

\section{METHOD}

Our study compared patients being discharged from forensic psychiatric hospitals in four countries - Canada, Finland, Germany and Sweden - with patients with the same primary diagnosis, gender and age being discharged from general psychiatric services in the same geographic region as the forensic hospitals. Consistent with findings from the epidemiological investigations cited above, almost all of the patients from the forensic hospitals were men and almost all had a principal diagnosis of schizophrenia, schizoaffective disorder or schizophreniform disorder. Consequently, the present study included only those men with these three diagnoses. Three questions were addressed.

(a) Were men with schizophrenia who committed serious violent offences that led to treatment in forensic settings previously in general psychiatric care?

(b) What proportion of men with schizophrenia treated by general psychiatric services have a record of criminality? (c) Were problems present at the time of admission to general psychiatric care that indicated the need for treatments and services designed to prevent criminality?

\section{Study procedure}

Within each study site, each patient with a diagnosis of a major mental disorder about to be discharged from the forensic hospital was invited to participate in the study. If the patient formally consented to take part, a structured diagnostic interview was completed. If the diagnosis of a major mental disorder was confirmed, the participant was included in the study; the other interviews and assessments were completed and information was collected from patient records and family members. For each forensic patient recruited, a patient from a general psychiatric hospital in the same geographical region of the same gender and age ( \pm 5 years) and with the same principal diagnosis was identified and invited to participate. The same information was then collected from both sets of patients. Participants were asked for permission to contact their mother or an older sibling to collect family and childhood histories of them and their families. If the participant agreed, the relative was invited to participate.

\section{Participants}

The sample consisted of 158 consecutively discharged male patients with diagnoses of schizophrenia, schizophreniform and schizoaffective disorder who had received inpatient care from the forensic psychiatric hospital in one of the four sites. The study sites were selected because almost all - if not all-people with mental illness who are accused of crimes in these catchment areas are assessed prior to trial and sentenced to psychiatric treatment if the court is convinced that the person has committed the crime (Hodgins et al, 2004). Seventyfour men with the same primary diagnosis and age were recruited from general psychiatric hospitals in the same geographical regions as the forensic hospitals. In total 232 patients consented (Canada, $n=90$; Germany, $n=63$; Finland, $n=57$; Sweden, $n=22$ ), representing, $72.8 \%$ of the male forensic patients and $57.8 \%$ of the male general psychiatric patients who were invited to participate in the study. All participants gave written informed consent to be interviewed at study entry and on five 
occasions during the 24 months after discharge, authorised access to medical and criminal records, and named a family member to provide information about them.

\section{Information collected at discharge}

Information on socio-demographic characteristics, mental disorders, criminality and substance misuse among parents and siblings, and problems and academic performance during childhood and adolescence was collected from the patient, his family, and from his school, medical and social service files. Information about all previous psychiatric treatment was extracted from hospital files. Information on criminality was extracted from official criminal files; crimes included both those that led to convictions and those leading to judgments of non-responsibility due to mental illness or diminished responsibility. Violent crimes were defined as all offences causing physical harm, threats of violence or harassment, all types of sexual aggression, illegal possession of firearms or explosives, all types of forcible confinement, arson and robbery. All other crimes were defined as non-violent.

Primary, secondary and tertiary diagnoses, lifetime and current, were made using the Structured Clinical Interview for DSM-IV (SCID) for both Axis I and Axis II disorders (Spitzer et al, 1992). The SCID interview was administered by experienced psychiatrists trained to use this diagnostic interview protocol by those who developed the instrument.

Once all of the information had been collected from files, relatives and participants, the psychiatrist who had administered the SCID and assessed symptoms rated the case using the Psychopathy Checklist - Revised (PCL-R; Hare, 1991). Upon completion of training to use this instrument, psychiatrists were examined by rating English-language videotapes of interviews and case vignettes. The PCL- $\mathrm{R}$ includes 20 items, each rated 0,1 or 2 . Factor analyses have indicated that psychopathy is composed of two personality traits and an impulsive and irresponsible lifestyle (Cooke \& Michie, 2001). The two personality traits are presumed to emerge early in life and to be stable over time (Blair, 2003). In our study only the score for Deficient Affective Experience was used, our hypothesis being that it is associated with repetitive violence. The Deficient Affective Experience score is the total score for four items: 'lack of remorse or guilt', 'shallow affect', 'callous/lack of empathy' and 'failure to accept responsibility for own actions'.

\section{RESULTS}

\section{History of prior treatment in general psychiatry}

Of the 158 patients recruited from the forensic psychiatric hospitals, 123 $(77.8 \%)$ had been admitted to a general psychiatric service at least once before committing the offence that led to admission to forensic psychiatric care (Fig. 1), with a mean of 5.6 admissions (s.d.=6.6). These 123 patients (GP-FP group) did not differ from the 35 patients with no prior admission to general psychiatric care with respect to age (GP-FP group: mean 40.0 years, s.d.=11.6; no prior admission group: mean $=38.1$ years, s.d. $=10.01$; $t(156)=-0.902, P=0.368)$ and the proportion born outside the site country (10.6\% v. $\left.17.1 \% ; \chi^{2}(1)=1.113, P=0.291\right)$.

\section{Criminal records of general psychiatric patients}

Of the 74 general psychiatric patients, 18 $(24 \%)$ had a record of at least one criminal offence.

\section{Offending prior to first general psychiatric admission}

Ten of the general psychiatric patients $(13 \%)$ had committed at least one offence before their first admission to general psychiatric care and another $8(11 \%)$ had committed their first offence after their first admission. Among the 123 GP-FP patients, $49(39.8 \%)$ had committed their first offence before their first admission to a general psychiatric ward; $21(17.1 \%)$ had committed their first offence after their first admission to general psychiatric care but before the crime that led to admission to a forensic hospital; and the remaining 53 $(43.1 \%)$ committed their first criminal

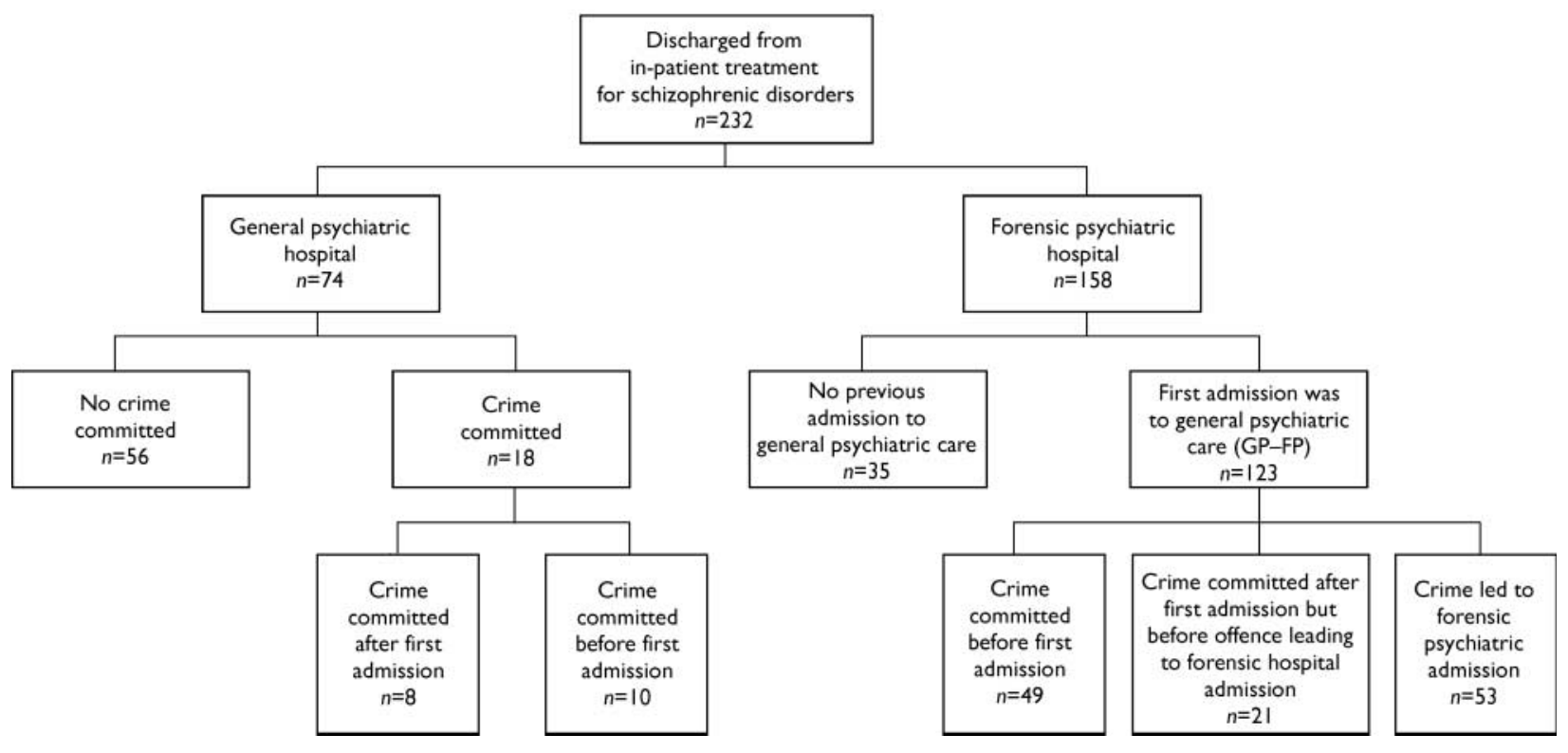

Fig. I Profile of study sample. 
offence some time after their first admission to general psychiatry, and the commission of this offence led to admission to a forensic hospital.

Ten general psychiatric patients and 49 GP-FP patients had a record of criminal offending before their first admission to general psychiatric services. We examined their criminal activities during the period when they were in and out of general psychiatric care (for the GP-FP group, we excluded the offence that led to admission to the forensic hospital). After their first admission to general psychiatric care, these 59 patients had committed 195 non-violent and 59 violent offences. In the GP-FP group, 70 patients had committed at least one crime before the offence that led to their admission to a forensic psychiatric hospital. Before committing the crime that led to this admission, these 70 patients had committed 270 non-violent crimes and 75 violent crimes. In addition to the offences counted above, the GP-FP patients committed on average 2.5 violent and 2.7 non-violent offences and those treated only in forensic psychiatric care committed 2.7 violent and 8.1 non-violent offences that gained them admission to a forensic hospital. Twenty-seven of the GP-FP group $(22 \%)$ and $9(26 \%)$ of the forensic care only group were admitted to forensic hospital following the commission of murder or attempted murder.

\section{Were problems present at first general psychiatric admission that indicated needs for specific anti-crime interventions?}

Table 1 presents comparisons between the group of participants (general psychiatric and GP-FP patients) who had committed crimes before their first admission to general psychiatric services and those with no criminal record. Patients in the former group were, on average, 5 years older at study entry than those with no record of criminal offending, and were also older at first admission. Proportionately more of those who had committed one or more offences before their first admission to general psychiatric care compared with the non-offenders were characterised by behavioural problems during childhood and adolescence, substance misuse before age 18 years, a diagnosis of alcohol abuse or dependence at first admission, and antisocial personality disorder. These characteristics would have been present at the time of first admission. A logistic regression equation was calculated to predict crime $v$. no crime, including the general psychiatry and GP-FP patients who had committed a crime before first admission to general psychiatry and the non-offenders. The predictors included only characteristics that would have been present and measurable at the time of first admission and that distinguished crime/no crime groups in univariate analyses. Three categorical variables were entered as predictors: antisocial personality disorder, being institutionalised before age 18 years and a diagnosis of alcohol abuse or dependence at first admission. Age at study entry was used as a control variable. A diagnosis of antisocial personality disorder increased the risk of offending 6.05 times (95\% CI 1.92-19.04), having been institutionalised before age 18 years increased it 2.89 times $(95 \%$ CI 1.05 $10.84)$ and a diagnosis of alcohol dependence at first admission, 4.06 times $(95 \%$ CI 1.52-10.82). Of the 59 patients who had offended before their first admission, $14(23.7 \%)$ were not characterised by any of the four predictors, $19(32.2 \%)$ were characterised by one predictor, $23(39.0 \%)$ by two predictors and $3(5.1 \%)$ by three predictors. The model could not be improved upon to a statistically significant degree by the addition of any further variables and yielded an overall likelihood ratio of $35.38(P<0.001)$.

Patients who had committed crimes before their first admission to general psychiatric care differed from those with no history of crime at study entry as to their score on the PCL-R for the trait of Deficient Affective Experience (Table 1). It is likely that this trait would have been present at the time of first admission. The data do not permit us to establish the dates

Table I Comparisons of men with schizophrenia who had or had not committed a criminal offence before first admission to general psychiatric services

\begin{tabular}{|c|c|c|c|}
\hline & $\begin{array}{l}\text { Crime before first } \\
\text { admission }(n=59)\end{array}$ & No crime $(n=56)$ & \\
\hline Age at data collection (years): mean (s.d.) & $41.2(11.79)$ & $35.1(10.62)$ & $t(I, I I 3)=-2.935 P=0.004$ \\
\hline \multicolumn{4}{|l|}{ Characteristics at time of first admission } \\
\hline Born outside site country, \% & 8.5 & 14.3 & $\chi^{2}=0.968(n=115) P=0.325$ \\
\hline Age at first hospitalisation (years): mean (s.d.) & $27.2(8.24)$ & $24.0(7.42)$ & $t(I, I I 2)=-2.147 P=0.034$ \\
\hline Age at onset of prodrome (years): mean (s.d.) & $21.4(5.13)$ & $20.0(6.14)$ & $t(I, 42)=-0.84 I P=0.405$ \\
\hline Age at onset of schizophrenia (years): mean (s.d.) & $24.7(7.60)$ & 22.90 (7.09) & $t(1,96)=-1.231 P=0.228$ \\
\hline Diagnosis of alcohol abuse/dependence, \% & 49.2 & 14.3 & $\chi^{2}=16.005(n=115) P<0.001$ \\
\hline \multicolumn{4}{|l|}{ Problems present before age 18 years } \\
\hline Behaviour problems at home, $\%$ & 57.6 & 28.6 & $\chi^{2}=9.870(n=115) P=0.002$ \\
\hline Behaviour problems at school, \% & 54.2 & 33.9 & $\chi^{2}=4.80 I(n=I 15) P=0.030$ \\
\hline Behaviour problems in the community, $\%$ & 49.2 & 16.1 & $\chi^{2}=14.211(n=115) P<0.00 I$ \\
\hline Substance misuse, $\%$ & 60.3 & 39.3 & $\chi^{2}=5.5054(n=I 14) P=0.025$ \\
\hline Institutionalised, \% & 39.7 & 17.9 & $\chi^{2}=6.582(n=114) P=0.010$ \\
\hline Poor parenting, \% & 28.8 & 12.7 & $\chi^{2}=6.881(n=114) P=0.032$ \\
\hline Diagnosis of conduct disorder, \% & 37.3 & 10.7 & $\chi^{2}=11.015(n=115) P=0.00 I$ \\
\hline \multicolumn{4}{|l|}{ Characteristics at study entry } \\
\hline Antisocial personality disorder, \% & 39.0 & 8.9 & $\chi^{2}=14.089(n=115) P<0.001$ \\
\hline Drug abuse/dependence, \% & 59.3 & 26.8 & $\chi^{2}=12.376(n=115) P<0.001$ \\
\hline Deficient Affective Experience score: mean (s.d.) & $4.3(2.04)$ & $2.63(2.08)$ & $t(I, I I 2)=-4.376 P<0.00 I$ \\
\hline
\end{tabular}


when patients first met diagnostic criteria for drug misuse and/or dependence.

\section{Were problems present during general psychiatric in-patient treatment that indicated needs for specific anti-crime interventions?}

A regression equation similar to that described above was calculated. Included in these analyses were the general psychiatric and GP-FP patients who had a record of criminality beginning after their first admission to general psychiatric care but (for the GP-FP group) before the crime that led to admission to a forensic hospital, and the general psychiatric patients who had committed no crime. The predictors included only characteristics that would have been present and measurable at the time of treatment in general psychiatry and that distinguished crime/no crime groups in univariate analyses at $P=0.25$ or less. Only two factors entered the model. The model could not be improved upon to a statistically significant degree by the addition of any further variables and yielded an overall likelihood ratio statistic of $\mathbf{1 7 . 4 1}$ $(P=0.001)$. Behaviour problems in the community before age 18 years increased the risk of criminality 5.8 times $(95 \%$ CI 1.79-18.99) and a diagnosis of alcohol abuse or dependence at first admission increased the risk 4.3 times $(95 \%$ CI 1.27-14.53).

\section{DISCUSSION}

The study recruited men with schizophrenia, schizophreniform disorder or schizoaffective disorder at discharge from forensic and general psychiatric hospitals in four countries. Seventy-eight per cent of the forensic patients had been admitted to general psychiatric wards before committing the offence that led to their admission to a forensic hospital. Twenty-four per cent of the general psychiatric patients had a record of criminal activity. Although $14 \%$ of the general psychiatric patients had committed an offence before their first admission to general psychiatry, $40 \%$ of the forensic patients admitted to general psychiatry had done so. The number of offences committed by these men during the period when they were receiving care from general psychiatric services is notable. These findings compel us to develop policies and procedures to identify patients engaging in antisocial and criminal behaviours and to provide them with interventions to prevent such behaviours. The human and financial costs of waiting to intervene until they commit a serious, violent offence are too high to tolerate.

Patients who have committed an offence before their first admission to general psychiatric services can be easily identified, either by asking them about their history of crime in a sympathetic yet challenging manner or by consulting official criminal records. As past criminality is the best predictor of future criminality (Bonta et al, 1998), this information should signal a need for additional assessment, and for treatment, supervision and community placements designed to reduce antisocial behaviours. Failing to collect information on prior offending leads to the unacceptable situation described above, in which the complexity of the disorders presented by such individuals is not recognised and the necessary treatments and services are not provided.

Univariate comparisons indicated differences between patients offending before first admission to general psychiatric care and non-offending general psychiatric patients on problems present before age 18 years, alcohol abuse or dependence at first admission, antisocial personality disorder and Deficient Affective Experience score. A multivariate model of factors associated with criminal offending before first admission to general psychiatry services identified predictors that index antisocial behaviour (including substance misuse) that emerges in childhood and escalates in severity culminating in criminal offending. The diagnosis of antisocial personality disorder is given when an individual presents a 'pervasive pattern of disregard for and violation of the rights of others occurring since age 15 years' (American Psychiatric Association, 1994) and behaviours present before age 15 years that meet criteria for a diagnosis of conduct disorder as indicated by 'repetitive and persistent pattern of behaviour in which the rights of others or major age-appropriate societal norms or rules are violated' (American Psychiatric Association, 1994). Prospective, longitudinal investigations conducted in several different countries have observed that approximately $5 \%$ of males display antisocial behaviour from early childhood which escalates in severity with age, until criminal offending begins during adolescence (Moffitt, 1993). Such men commit most of the crimes that are committed (Kratzer \& Hodgins, 1999). Even at young ages, the antisocial behaviour is accompanied by personality traits, callousness and insensitivity to others, novelty-seeking and cognitive deficits (Moffitt \& Caspi, 2002). These men meet criteria for conduct disorder in childhood and/or adolescence and for antisocial personality disorder in adulthood. For reasons that are currently not understood, both antisocial personality disorder - and by definition conduct disorder - are much more prevalent among men who develop schizophrenia than among men in the general population (Robins et al, 1991; Kim-Cohen et al, 2003).

At first admission, once the acute symptoms of psychosis have been reduced, assessment of childhood, adolescent and adult patterns of antisocial behaviour, attitudes and the personality traits associated with these patterns of behaviour is indicated. In our study, such an assessment would have demonstrated that patients who had already offended before their first admission presented needs for specific treatments aimed at reducing antisocial behaviours and attitudes, and increasing pro-social skills. Cognitive-behavioural programmes targeting these attitudes and behaviours have been shown to be effective in offenders who are not mentally ill (McGuire, 1995), and are being adapted and tested with offenders with schizophrenia. These patients also require an intervention aimed at ending misuse of alcohol, adapted both to the presence of schizophrenia and to antisocial attitudes and behaviours. Furthermore, once discharged to the community, these patients require more intense supervision to ensure that they take their medications and comply with other forms of treatment. Also, they need to be housed in neighbourhoods where they can neither easily associate with other offenders, nor access drugs and weapons (Silver, 2000).

Most general psychiatric services do not - and could not, at present - provide the kinds of treatments described above. General psychiatric services in most places would not have sufficient staff who are trained to conduct the type of assessments and implement the cognitive-behavioural programmes described, nor to provide the intense supervision required once patients are discharged to the community. Naturalistic follow-up studies indicate that court-ordered community treatment 
(Heilbrun \& Peters, 2000; Swanson et al, 2000) and legal powers to admit patients for short periods, involuntarily if necessary, contribute to reducing recidivism and prolonging safe community tenure (Hodgins et al, 1999). Such legal powers are useless, however, if in-patient beds are unavailable when needed. Further, general psychiatric services are often geographically based, so that patients are discharged to the neighbourhoods where they lived prior to admission, areas characterised by high rates of crime and drug use and low rates of employment.

The association of a stable pattern of antisocial behaviour with substance misuse is important. Children and adolescents who display conduct problems are exposed to alcohol and drugs earlier than others and an earlier onset of substance misuse is associated with persistence (Armstrong \& Costello, 2002). Even among people who do not have schizophrenia, the presence of antisocial personality disorder is associated with failure to benefit from substance misuse treatment (King et al, 2001). Thus, intervening as early as possible with programmes specifically adapted to the needs of the patients is imperative. Furthermore, among children at genetic risk of schizophrenia, prospectively collected data indicate that high doses of cannabis in adolescence significantly increase the risk of developing schizophrenia (Arseneault et al, 2004). In addition, evidence suggests that men with schizophrenia sustain damage to specific neural structures from lower amounts of alcohol compared with men with no mental disorder (Mathalon et al, 2002). Again, intervening early to reduce substance misuse is indicated.

Using comorbid diagnoses of conduct disorder and antisocial personality disorder is helpful in characterising a subgroup of patients with schizophrenia. These disorders, currently defined, index a stable pattern of antisocial behaviour that emerges early in life and remains stable well into adulthood (Simonoff $e t$ al, 2004). Men with schizophrenia who have displayed a stable pattern of antisocial behaviour from childhood have been shown to be similar to men with this behaviour pattern who do not develop schizophrenia, with respect to age at first crime and types and frequencies of crimes (Hodgins \& Côté, 1993). Although there is little research examining the differences between individuals with conduct disorder who do and who do not develop a schizophrenic disorder, such

\section{CLINICAL IMPLICATIONS}

- Men experiencing their first episode of schizophrenia or schizoaffective disorder should be assessed for conduct disorder in childhood (prior to age 15 years) and for antisocial personality disorder and substance use disorders.

Once psychotic symptoms are reduced, patients with a history of antisocial behaviour require cognitive-behavioural interventions aimed at changing antisocial behaviours and the associated attitudes and ways of thinking.

- These men require long-term care in communities that limit access to drugs and offenders and that support newly learned pro-social behaviours, attitudes and ways of thinking.

\section{LIMITATIONS}

- The forensic sample included only patients who had been discharged.

- Patients with schizophrenia and a childhood history of antisocial behaviour had a higher rate of refusal to participate than did patients with the same primary diagnosis but without a history of antisocial behaviour.

- Information on childhood and adolescence was obtained retrospectively.

S. HODGINS, PhD, Institute of Psychiatry, King's College, University of London, UK; R. MÜLLER-ISBERNER, Drmed, Haina Forensic Psychiatric Hospital, Haina, Germany

Correspondence: Professor S. Hodgins, Department of Forensic Mental Health Science, Institute of Psychiatry, Box PO23, De Crespigny Park, Denmark Hill, London SE5 8AF, UK. E-mail: s.hodgins@iop.kcl.ac.uk

(First received 12 November 2003, final revision 24 May 2004, accepted 3I May 2004)

differences are likely to be important, both for the development of effective treatments for antisocial behaviour and schizophrenia, and for advancing our understanding of aetiological factors. The repeated finding that it is more common for men who develop schizophrenia (compared with those who do not) to display an early-onset, stable pattern of antisocial behaviour suggests that there is a link between the two. This link and its determinants are poorly understood. Most importantly, there is no evidence, to our knowledge, about the response to early intervention programmes designed to reduce conduct problems among children who are at risk of later schizophrenia. If such childhood interventions were effective, they could reduce substance misuse in adolescence and thereby, perhaps, reduce the risk of schizophrenia. If schizophrenia developed, pro-social skills learned in a childhood intervention programme, along with the absence of antisocial behaviour and substance misuse, could have a positive impact on compliance with medication and the course of schizophrenia.

\section{ACKNOWLEDGEMENTS}

The Comparative Study of the Prevention of Crime and Violence by Mentally III Persons is being conducted by S. Hodgins, PhD, Institute of Psychiatry, King's College, London, UK; D. Eaves, MD, Vancouver, Canada; S. Hart, PhD, Simon Fraser University, Canada; R. Kronstrand, PhD, Rättsmedicinalverket and Linköping University, Sweden; R. MüllerIsberner, Drmed, Klinik für forensische Psychiatrie Haina, Germany; C. D. Webster, PhD, Simon Fraser University and McMaster University, Canada; R. Freese, MD, Klinik für forensische Psychiatrie Haina, Germany; A. Grabovac, MD, Riverview Hospital, Vancouver, Canada; D. Jöckel, Drmed, Klinik für forensische Psychiatrie Haina, Germany; A. Levin, MD, Forensic Psychiatric Hospital, British Columbia, Canada; E. Repo-Tiihonen, MD, PhD, Niuvanniemi Hospital, Finland; D. Ross, MSc, Riverview Hospital, Vancouver, Canada; P. Toivonen, MD, Vanha Vaasa 
Hospital, Finland; H. Vartiainen, MD, PhD, Helsink Central University Hospital, Finland; A. Vokkolainen, Vanha Vaasa Hospital, Finland; Jean-Francois Allaire, MSc, Institut Philippe Pinel de Montréal, Canada; A. Tengström, PhD, Maria-Ungdom Research Centre, Karolinska Institute, Sweden.

Grants to support this study have been awarded by the BIO-MED-II programme of the European Union; in Canada, by the Forensic Psychiatric Services Commission of British Columbia, the Mental Health, Law and Policy Institute, Simon Fraser University, Riverview Hospital; in Finland, by the Niuvanniemi and Vanha Vaasa State Mental Hospitals; in Germany, by the Deutsche Forschungsgemeinschaft, Institut für forensische Psychiatrie Haina; in Sweden, by the Medicinska Forskningrådet, Vårdatstiftelsen, National Board of Forensic Medicine, Forensic Science Centre, Linköping University, and Linköping University.

\section{REFERENCES}

American Psychiatric Association (1994) Diagnostic and Statistical Manual of Mental Disorders (4th edn) (DSM-IV). Washington, DC: APA.

Armstrong, T. \& Costello, E. J. (2002) Community studies on adolescent substance use, abuse, or dependence and psychiatric comorbidity. Journal of Consulting and Clinical Psychology, 70, 1224-1239.

Arseneault, L., Moffitt, T. E., Caspi, A., et al (2000) Mental disorders and violence in a total birth cohort. Archives of General Psychiatry, 5, 979-986.

Arseneault, L., Cannon, M., Witton, J., et al (2004) Causal association between cannabis and psychosis: examination of the evidence. British Journal of Psychiatry, 184, $110-117$.

Blair, R. J. R. (2003) Neurobiological basis of psychopathy. British Journal of Psychiatry, 182, 5-7.

Bonta, J., Law, M. \& Hanson, K. (1998) The prediction of criminal and violent recidivism among mentally disordered offenders: a meta-analysis. Psychological Bulletin, 123, 123-142.
Brennan, A., Mednick, S. A. \& Hodgins, S. (2000) Major mental disorders and criminal violence in a Danish birth cohort. Archives of General Psychiatry, 57, 494-500.

Cooke, D. J. \& Michie, C. (200I) Refining the construct of psychopathy: towards a hierarchical model. Psychological Assessment, 13, 17|-188.

Erb, M., Hodgins, S., Freese, R., et al (200I) Homicide and schizophrenia: maybe treatment does have a preventive effect. Criminal Behaviour and Mental Health, II, 6-26.

Hare, R. D. (1991) The Hare Psychopathy Checklist Revised. Toronto: Multi-Health Systems.

Heilbrun, K. \& Peters, L. (2000) The efficacy and effectiveness of community treatment programmes in preventing crime and violence among those with severe mental illness in the community. In Violence Among the Mentally III: Effective Treatments and Management Strategies (ed. S. Hodgins), pp. 34I-357. Dordrecht: Kluwer.

Hodgins, S. \& Côté, G. (1993) The criminality of mentally disordered offenders. Criminal Justice and Behavior, 28, I15-129.

Hodgins, S. \& Janson, C.-G. (2002) Criminality and Violence Among the Mentally Disordered: The Stockholm Metropolitan Project. Cambridge: Cambridge University Press.

\section{Hodgins, S., Lapalme, M. \& Toupin, J. (1999)}

Criminal activities and substance use of patients with major affective disorders and schizophrenia: a two-year follow up. Journal of Affective Disorders, 55, 187-202.

Hodgins, S., Tengström, A., Östermann, R., et al (2004) An international comparison of community treatment programs for mentally ill persons who have committed criminal offences. Criminal Justice and Behavior, in press.

Kim-Cohen, J., Caspi, A., Moffitt, T. E., et al (2003) Prior juvenile diagnoses in adults with mental disorder. Archives of General Psychiatry, 60, 709-714.

King, V. L., Kidorf, M. S., Stoller, K. B., et al (200I) Influence of antisocial personality subtypes on drug abuse treatment response. Journal of Nervous and Mental Disease, 189, 593-60I.
Kratzer, L. \& Hodgins, S. (1999) A typology of offenders: a test of Moffitt's theory among males and females from childhood to age 30. Criminal Behaviour and Mental Health, 9, 57-73.

Mathalon, D. H., Pfefferbaum, A., Lim, K. O., et al

(2002) Compounded brain volume deficits in schizophrenia-alcoholism comorbidity. Archives of General Psychiatry, 60, 245-252.

McGuire, J. (1995) What Works: Reducing Reoffending - Guidelines from Research and Practice. Chichester: John Wiley \& Sons.

Moffitt, T. E. (1993) Adolescent-limited and life-course persistent antisocial behavior: a developmental taxonomy. Psychological Review, 100, 674-701.

Moffitt, T. E. \& Caspi, A. (2002) Childhood predictors differentiate life-course persistent and adolescencelimited antisocial pathways among males and females. Development and Psychopathology, I3, 355-375.

Mullen, P. E., Burgess, P., Wallace, C., et al (2000) Community care and criminal offending in schizophrenia. Lancet, 355, 614-617.

Robins, L. N., Tipp, J. \& Przybeck, T. (1991) Antisocial personality. In Psychiatric Disorders in America: The Epidemiologic Catchment Area Study (eds L. N. Robins \& D. Reiger), pp. 258-290. New York: Macmillan/Free Press.

Silver, E. (2000) Race, neighbourhood disadvantage, and violence among persons with mental disorders: the importance of contextual measurement. Law and Human Behavior, 24, 449-456.

Simonoff, E., Elander, J., Holmshaw, J., et al (2004) Predictors of antisocial personality: continuities from childhood to adult life. British Journal of Psychiatry, 184 II8-127.

Spitzer, R. L., Williams, J. B.W., Gibbon, M., et al (1992) The structured clinical interview for DSM-III-R (SCID) I: History, rationale, and description. Archives of General Psychiatry, 49, 624-629.

Swanson, J.W., Swartz, M. S., Wagner, H. R., et al (2000) Involuntary out-patient commitment and reduction of violent behaviour in persons with severe mental illness. British Journal of Psychiatry, 176, 324-331. 